\title{
Presence of Renin Secretory Granules in Rat Adrenal Gland and Stimulation of Renin Secretion by Angiotensin II but Not by Adrenocorticotropin
}

\author{
Kenji Mizuno, Loren H. Hoffman, James C. McKenzie, and Tadashi Inagami \\ Departments of Biochemistry and Cell Biology, Vanderbilt University School of Medicine, Nashville, Tennessee 37232; \\ Department of Anatomy, Howard University College of Medicine, Washington, DC 20059
}

\begin{abstract}
Renin has been identified biochemically and immunohistochemically in the adrenal gland. We examined the subcellular distribution and behavior of adrenal renin. By differential centrifugation of adrenal capsules, we found renin mainly in mitochondrial fractions. By Percoll density gradient centrifugation of this fraction, dense granules were separated from mitochondria and microsomes. The renin activity in the dense granules from the capsules of nephrectomized rats was 15 times greater than that of the intact rat. Immunohistochemical studies revealed that the dense granules increased in number after bilateral nephrectomy. Immunogold staining of these granules showed unequivocally the presence of renin in these granules. Adrenal capsules in organ culture were found to release renin at a steady rate. Renin release from bilaterally nephrectomized rat adrenals was $\mathbf{4 6}$ times faster than from the organs of intact animals. The mechanism of the control of renin secretion from the adrenal gland was different from the kidney in that the secretion was stimulated by potassium chloride $(10 \mathrm{mM})$ or angiotensin II $\left(10^{-9}-10^{-7} \mathrm{M}\right)$ but not by ACTH $\left(10^{-9}-10^{-7}\right.$ $M)$, suggesting stimulation by intracellular calcium. These results provide evidence that the adrenal synthesizes renin, stores it in specific secretory granules and secretes it in a regulated manner.
\end{abstract}

\section{Introduction}

Renin has been recognized as a plasma enzyme released from the kidney. It mediates the first step of angiotensin formation by cleaving the decapeptide angiotensin I (Ang I) ${ }^{1}$ from the macromolecular prohormone angiotensinogen in a highly specific manner. Ang $I$ is further converted to the active octapeptide angiotensin II (Ang II) by a converting enzyme. Ang II is a potent vasoconstrictor and aldosterone secretagogue. Thus, renin plays a central role in blood pressure regulation. On the other hand, recent biochemical and immunological studies revealed that renin exists in the adrenal gland of various mammalian species (1-5). It was also demonstrated that this adrenal renin is primarily located in the zona glomerulosa cells

Address reprint requests to Dr. Inagami, Department of Biochemistry, Vanderbilt University School of Medicine, Nashville, TN 37232.

Received for publication 15 January 1988 and in revised form 13 April 1988.

1. Abbreviations used in this paper: Ang I, angiotensin I; PMSF, phenylmethanesulfonyl fluoride.

J. Clin. Invest.

(c) The American Society for Clinical Investigation, Inc.

0021-9738/88/09/1007/10 \$2.00

Volume 82, September 1988, 1007-1016 rather than the fasciculata or medullary cells $(6,7)$. Further, the adrenal renin has been reported to increase markedly after high potassium loading or after nephrectomy (7-9), when plasma renin activity was at undetectable levels. These findings suggest that the adrenal renin is not merely due to contamination by plasma renin of renal origin but endogenous to the adrenal. In support of this, messenger RNA for renin has been detected in the adrenal gland (10).

However, the functional significance of renin in adrenal is not clear. Only a few reports $(7,9)$ suggested that the renin is involved in the production of aldosterone, presumably through intraadrenal generation of Ang II by renin, but no concrete evidence for such function of renin in this tissue has yet been obtained. Also unknown is whether the renin is secreted from the adrenal. This intriguing question is raised by the findings of the presence of renin-like activity and of immunoreactive Ang I and Ang II in the plasma of anephric subjects (11-13), and the hypotensive response to converting enzyme inhibitor, captopril, by a sodium-depleted anephric subject (14), suggesting that renin or renin-like enzymes synthesized in extrarenal tissues may contribute to the generation of plasma angiotensin. In view of these interesting issues, we tested the hypothesis that there exist renin-secretory granules in the adrenal. We show here in rat adrenals that renin was identified in the dense granules and that in the cultured adrenal capsular tissues, renin release was found and stimulated by potassium and Ang II, but not by ACTH. The data suggest that renin is localized in the storage granules of the adrenal presumably to be released into the extracellular space, by a regulated mechanism.

\section{Methods}

Animals. Male Sprague-Dawley rats (Harlan Sprague-Dawley, Indianapolis, IN) weighing 180-220 g were used for the experiments. The rats were maintained on a regular Purina chow diet (Ralston Purina Co., St. Louis, MO) containing $0.39 \%$ sodium and $0.9 \%$ potassium and allowed free access to tap water. Bilateral nephrectomy was performed with some of the rats under sodium pentobarbitol anesthesia (30 $\mathrm{mg} / \mathrm{kg}$ i.p.) $32 \mathrm{~h}$ before they were killed.

Fractionation by differential centrifugation. Normal and nephrectomized rats were anesthetized with sodium pentobarbital $(30 \mathrm{mg} / \mathrm{kg}$ i.p.). The adrenal glands were removed immediately after the rats were perfused with ice-cold saline $(\sim 150 \mathrm{ml})$ for a period of $15 \mathrm{~min}$ through the abdominal aorta by using an infusion pump (Cole-Parmer Instrument Co., Chicago, IL) and the adrenal capsules were prepared by manual compression using nylon gauze (pore size, $100 \mu \mathrm{m}$; Spectrum Medical Industries Inc., Los Angeles, CA). All the following steps were performed at $4^{\circ} \mathrm{C}$. The capsular tissues from 10 to 12 adrenals were cut into small pieces $(\sim 2 \times 2 \mathrm{~mm})$ and homogenized gently in 6 $\mathrm{ml}$ of ice-cold $0.25 \mathrm{M}$ sucrose containing $30 \mathrm{mM}$ Tris- $\mathrm{HCl}$ and $1 \mathrm{mM}$ $\mathrm{Na}_{2}$-EDTA, $\mathrm{pH} 7.4$, with a motor-driven Potter-Elvehjem grinder for 30 strokes at $500 \mathrm{rpm}$. The crude homogenate (hereafter called "original homogenate") was then subjected to subsequent fractionation. 
After separating the unbroken cells, cell debris and capsular fragments $\left(P_{0}\right)$ by centrifugation of the original homogenate at $70 \mathrm{~g}$ for 10 $\mathrm{min}$, the supernatant was centrifuged at $600 \mathrm{~g}$ for $10 \mathrm{~min}$. The pellet was homogenized again in $3 \mathrm{ml}$ of the sucrose solution under the same conditions as described above and recentrifuged at $600 \mathrm{~g}$ for $10 \mathrm{~min}$ to remove the nuclear fraction $\left(P_{1}\right)$ in the pellet. The supernatant was combined $(\sim 9 \mathrm{ml})$ and further centrifuged at $5,200 \mathrm{~g}$ for $20 \mathrm{~min}$ to obtain a heavy mitochondrial fraction $\left(P_{2}\right)$ in the pellet. The $P_{2}$ pellet was washed twice by resuspension in $3 \mathrm{ml}$ of the sucrose solution and recentrifugation at $5,200 \mathrm{~g}$ for $20 \mathrm{~min}$. The resulting supernatant $\left(\mathrm{S}_{2}\right.$, $\sim 15 \mathrm{ml}$ ) was centrifuged at $12,000 \mathrm{~g}$ for $20 \mathrm{~min}$ to obtain a light mitochondrial fraction $\left(\mathbf{P}_{2}\right)$, and then the supernatant was further centrifuged at $105,000 \mathrm{~g}$ for $60 \mathrm{~min}$ to separate the microsomal fraction (M) from the cytosolic fraction (S).

Density gradient centrifugation. The $\mathrm{P}_{2}$ pellet was gently dispersed in $1 \mathrm{ml}$ of the sucrose solution, and $0.5-\mathrm{ml}$ of the solution was added to $7.5 \mathrm{ml}$ of $35 \%$ Percoll (Sigma Chemical Co., St. Louis, MO) containing $0.25 \mathrm{M}$ sucrose, $1 \mathrm{mM} \mathrm{Na}$-EDTA and $30 \mathrm{mM}$ Tris- $\mathrm{HCl}, \mathrm{pH}$ 7.4. The Percoll gradient was initiated by centrifugation at $30,000 \mathrm{~g}$ for $30 \mathrm{~min}$ in an angle-head rotor (50 Ti; Beckman Instruments, Palo Alto, CA). A tube containing standard density beads (Sigma Chemical Co.), which had been constituted in distilled water $(0.5 \mathrm{ml})$ and then each of them $(5 \mu \mathrm{l})$ was applied to the Percoll/sucrose solution, was placed in the same rotor and centrifuged simultaneously. The sedimentation density of the subcellular particles within the gradient was determined by comparison with the location of the density beads. After centrifugation, the sample was fractionated into 10 fractions $(0.8 \mathrm{ml}$ each) by pipetting.

Measurement of enzyme activities and protein content. Samples from differential and density gradient centrifugation were treated with 0.1 vol of phosphate buffer $(0.2 \mathrm{M}, \mathrm{pH} 7.0)$ containing $1 \%$ Triton $\mathrm{X}-100$ before assay. Specific immunoreactive renin activity was determined using antirenin antibody to distinguish it from nonspecific renin-like activity of proteases according to the method previously detected $(4,5,15,16) .25$ to $50 \mu \mathrm{l}$ of the samples were incubated with $10 \mu l$ of diluted (1:500) rabbit antiserum raised against pure rat kidney renin (17) at $4^{\circ} \mathrm{C}$ for $20 \mathrm{~h}$. This antibody used resulted in $50 \%$ inhibition of renin activity ( $40.0 \mathrm{ng}$ Ang $\mathrm{I} / \mathrm{h}$ ) in a rat kidney extract at a dilution of 1:10,000 and complete inhibition at a dilution of 1:1,000. For controls, the same sample was incubated with preimmune rabbit serum at the same dilution. The pretreated sample was incubated at $37^{\circ} \mathrm{C}$ for $1 \mathrm{~h}$ (in case of fractions from differential centrifugation) or for $4 \mathrm{~h}$ (fractions from density gradient) with $75 \mu \mathrm{l}$ of unfractionated plasma of bilaterally nephrectomized rats as renin substrate in $0.2 \mathrm{M}$ phosphate buffer, pH 7.0, containing $10 \mathrm{mM} \mathrm{Na} \mathbf{2}_{2}$-EDTA and $1 \mathrm{mM}$ phenylmethanesulfonyl fluoride (PMSF). The generated Ang I was measured by radioimmunoassay (18). The recovery of added Ang I $(5.0 \mathrm{ng})$, incubated with original homogenates for $1 \mathrm{~h}$ at $37^{\circ} \mathrm{C}$, was $92.8 \pm 3.1 \%$ (mean $\pm \mathrm{SE}, n=3$ ). Therefore, significant angiotensinase inhibition was achieved under the conditions employed. The interand intraassay coefficients of variation for the renin assay over the measured range were $7.3 \pm 1.3 \%$ and $6.2 \pm 0.9 \%$ (mean $\pm \mathrm{SE}, n=10$ ), respectively. The difference in the renin activity of the sample preincubated with preimmune rabbit serum and that with anti-renin antiserum was defined as specific renin activity. The renin-like activity in each fraction obtained from differential and density gradient centrifugation was almost completely ( $>98 \%$ of the total renin-like activity) inhibited by antirenin antibody under the present conditions, indicating that specific renin activity comprises the majority of the renin-like activity. The specific renin activity is expressed in terms of nanograms Ang $\mathrm{I} \cdot \mathrm{mg}$ of protein ${ }^{-1} \cdot \mathrm{h}^{-1}\left(\right.$ or $\left.4 \mathrm{~h}^{-1}\right)$.

Acid phosphatase activity as a lysosomal marker enzyme was measured at pH 4.8 with p-nitrophenyl phosphate as substrate (19), and the activity is expressed as absorbance of p-nitrophenol measured at $\mathbf{4 1 0}$ $\mathrm{nm}$. Succinate dehydrogenase activity was measured as a mitochondrial marker according to the method of Slater and Bonner (20), and the activity is reported as the decrease of absorbance of ferricyanide at $450 \mathrm{~nm}$. In preliminary experiments, we confirmed that these enzyme activities were not influenced by the addition of Percoll solutions under conditions used in the present assay system. The protein concentration was determined by the method of Lowry et al. (21), using BSA (crystallized and lyophilized, Sigma Chemical Co.) as the standard.

Immunocytochemistry. Immunocytochemical studies were performed on (a) localization of renin in the adrenal cortex to confirm the presence of renin in the capsular (i.e., zona glomerulosa) tissues and (b) subcellular particles prepared by Percoll density gradient centrifugation.

For localization of renin in the adrenal, male Sprague-Dawley rats (200-250 g) were nephrectomized bilaterally $48 \mathrm{~h}$ before euthanasia by exsanguination under pentobarbital anesthesia $(30 \mathrm{mg} / \mathrm{kg}$ i.p.). Rats were perfused with $150 \mathrm{ml}$ Tyrode's buffer ( $\mathrm{pH} \mathrm{7.4)} \mathrm{followed} \mathrm{by} 250 \mathrm{ml}$ ice-cold Perfix (Fisher Scientific Co., Pittsburgh, PA). Adrenal glands were excised, routinely embedded in Paraplast Plus (Polysciences, Inc., Warrington, PA), sectioned at $5 \mu \mathrm{m}$ and mounted on acid-cleaned, gelatin/alum-coated glass slides. Immunohistochemical staining for renin was performed using an antibody against purified rat kidney renin (17) at a dilution of $1: 500$, and $A B C$ kits purchased from Vector Laboratories (Burlingame, CA) as previously described (22). Controls included serial dilution of antibody and substitution of normal rabbit serum for antirenin antibody.

To separate subcellular particles from Percoll solutions which contain silica coated with polyvinylpyrrolidone, a fractionated sample was centrifuged at $100,000 \mathrm{~g}$ for $90 \mathrm{~min}$ at $4^{\circ} \mathrm{C}$ with an angle-head rotor $(50$ Ti). The particles which remained above the hard pellet were carefully collected by pipetting, transferred to a medium consisting of $0.25 \mathrm{M}$

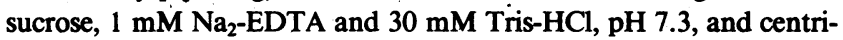
fuged again at $15,000 \mathrm{~g}$ for $30 \mathrm{~min}$ at $4^{\circ} \mathrm{C}$. The supernatant was decanted, after which the pellet was fixed for $2 \mathrm{~h}$ at $4^{\circ} \mathrm{C}$ in $3 \%$ glutaraldehyde buffered in $0.12 \mathrm{M}$ sodium cacodylate, $\mathrm{pH}$ 7.3. After buffer rinses, they were post-fixed in $1 \% \mathrm{OsO}_{4}$ in the same buffer for $1 \mathrm{~h}$. Samples were dehydrated with ascending concentrations of ethanol, treated with propylene oxide and embedded in Embed 812 (Electron Microscopy Sciences, Fort Washington, PA). Purified aldehyde solutions and $\mathrm{OsO}_{4}$ were supplied by Ladd Research Industries, Inc., Burlington, VT. Thin sections showing silver-gray interference colors were obtained from appropriate regions in the pellets, stained with uranyl acetate and lead citrate, and examined at $75 \mathrm{kV}$ in a Hitachi-600 transmission electron microscope (Hitachi, Tokyo, Japan).

For electron microscopic immunolocalization of renin, the Percoll fractions were fixed at $4^{\circ} \mathrm{C}$ in $4 \%$ formaldehyde $/ 0.25 \%$ glutaraldehyde in sodium cacodylate buffer for $30 \mathrm{~min}$, then for an additional $6 \mathrm{~h}$ in the fixative lacking glutaraldehyde. $\mathrm{No} \mathrm{OsO}_{4}$ postfixation was employed. Samples were treated with $0.5 \%$ sodium borohydride for 30 min to reduce unreacted aldehyde groups, then rinsed extensively in buffer, dehydrated as above and embedded. The epoxy resin was polymerized at $45^{\circ} \mathrm{C}$. Thin sections showing silver interference were mounted on nickel grids. These were treated for $30 \mathrm{~min}$ with saturated sodium metaperiodate (23) or for $45 \mathrm{~s}$ with $4 \%$ potassium methoxide (24) to partially etch the epoxy resin. Grids were incubated in Trisbuffered saline (TBS, $20 \mathrm{mM}$ Tris- $\mathrm{HCl}, 150 \mathrm{mM} \mathrm{NaCl}$, pH 7.6) containing $5 \%$ normal goat serum, then reacted with the rabbit anti-rat renin antibody for $18 \mathrm{~h}$ at $4^{\circ} \mathrm{C}$. Renin antiserum was used at a dilution of $1: 100$ or $1: 1,000$ in TBS/0.1\% bovine serum albumin (BSA, crystalized, globulin-free; Sigma Chemical Co.) containing $1 \%$ normal goat serum. Control preparations were treated with comparable dilutions of preimmune rabbit serum. After extensive rinses in TBS/BSA, the grids were treated for $1 \mathrm{~h}$ with goat anti-rabbit IgG complexed with $10 \mathrm{~nm}$ gold particles (E-Y Laboratories, Inc., San Mateo, CA). The immunoglobulin-gold complex was diluted 1:20 with TBS/BSA and centrifuged at $2,000 \mathrm{~g}$ for $20 \mathrm{~min}$ before use to remove aggregates. After rinsing in TBS/BSA, grids were reacted briefly with $3 \%$ glutaraldehyde, rinsed in water and stained with uranyl acetate and lead citrate.

Adrenal tissue culture. Male Sprague-Dawley rats weighing 200-250 $\mathrm{g}$ were used for the tissue culture. The rats were maintained on a regular Purina chow diet and allowed free access to tap water. 
Bilateral nephrectomy was performed under sodium pentobarbital anesthesia $(30 \mathrm{mg} / \mathrm{kg}$ i.p.) 24 to $28 \mathrm{~h}$ before sacrifice. The adrenal capsules were prepared in these rats as described above and transferred to Petri dishes $\left(9.6 \mathrm{~cm}^{2}\right.$, capsules from three adrenals per one dish). $1 \mathrm{ml}$ of RPMI 1640 medium supplemented with $0.1 \%$ BSA (RIA grade, Sigma Chemical Co.), $50 \mu \mathrm{g} / \mathrm{ml}$ gentamicin sulfate and $0.5 \mathrm{mM}$ PMSF (all in final concentration) were added to each dish. Cultures were maintained at $37^{\circ} \mathrm{C}$ under $95 \%$ air $/ 5 \% \mathrm{CO}_{2}$ for $8 \mathrm{~h}$ and the medium was totally exchanged at 2-h intervals. The medium obtained was immediately frozen with acetone/dry ice and stored at $-80^{\circ} \mathrm{C}$ until renin assay. Since it was reported that potassium, Ang II, and ACTH influenced adrenal renin content $(9,25)$, we further examined whether these substances induce renin secretion from the adrenal. Potassium chloride, Ang II ( ${ }^{5}$ lle-Ang II) and ACTH (human ACTH ${ }^{1-24}$ ), both from Peninsula Laboratories, Inc., Belmont, CA, were separately added to the medium to give a final concentration of $10 \mathrm{mM}$ for potassium chloride, $10^{-7}$ to $10^{-9} \mathrm{M}$ for Ang II and ACTH. The adrenal capsules were cultured in these media for a period of $8 \mathrm{~h}$, renewing the media at 2-h intervals. Cumulative renin activity was transformed from these fresh $2-\mathrm{h}$ samples and expressed as ng Ang $\mathrm{I} / 8 \mathrm{~h}$ incubation with substrate $/ 8 \mathrm{~h}$ tissue incubation/adrenal. Renin activity in the medium was determined by Ang I-generating activity essentially as described above except for the incubation period of renin-angiotensinogen reaction $\left(8 \mathrm{~h}\right.$ at $\left.37^{\circ} \mathrm{C}\right)$.

Statistical analysis. All data are expressed as the mean \pm SE. Statistical analysis was performed on data from the tissue culture experiments with one-way analysis of variance followed by $t$ test where appropriate for unpaired group. A $P$ value of 0.05 was considered to indicate a significant difference.

\section{Results}

\section{Subcellular distribution of renin}

Table I gives the average distribution of renin, marker enzymes, and protein in the fractions obtained by differential centrifugation of the homogenate from normal rat adrenal capsules. More than $60 \%$ of the total activity of renin was contained in $\mathrm{P}_{2}$. Similarly, about $60 \%$ of the total activity of succinate dehydrogenase was found in the $\mathrm{P}_{2}$ pellet. The acid phosphatase activity was dissociated from renin and succinate dehydrogenase activities, and more than $40 \%$ was contained in $\mathrm{S}_{2}$ supernatant. However, about $25 \%$ of the total activity still remained in the $P_{2}$, indicating that lysosomes were pelleted simultaneously in this fraction to some extent. As compared with the original homogenate, a threefold enrichment in specific activity of renin was obtained in $P_{2}$ (3.45 ng Ang I $\cdot \mathrm{mg}$ of protein $^{-1} \cdot \mathrm{h}^{-1}$ in original homogenate vs. $10.67 \mathrm{ng} \mathrm{Ang} \mathrm{I} \cdot \mathrm{mg}$ of protein ${ }^{-1} \cdot h^{-1}$ in $P_{2}$ ).

In order to determine if the renin activity was associated with the mitochondrial fraction, we further examined the subcellular distribution of renin in the adrenal from nephrectomized rats, since nephrectomy has been known to cause a marked increase in renin content of adrenal capsular tissue (9). As shown in Table II, renin activity in the original homogenate was very high as compared to that from normal rat adrenals and, approximately $75 \%$ of the total activity of renin was found in $\mathrm{P}_{2}$. As compared with the original homogenate, a 4.3-fold enrichment in specific activity of renin was obtained in $\mathrm{P}_{2}$ (37.41 $\mathrm{ng} \mathrm{Ang} \mathrm{I} \cdot \mathrm{mg}$ of protein ${ }^{-1} \cdot \mathrm{h}^{-1}$ in original homogenate $v s .159 .47 \mathrm{ng}$ Ang $\mathrm{I} \cdot \mathrm{mg}$ of protein ${ }^{-1} \cdot \mathrm{h}^{-1}$ in $\mathrm{P}_{2}$ ). Both the total and specific activities of renin in the $\mathrm{P}_{2}$ pellet were increased 15 -fold over those from normal rat adrenals. On the other hand, protein contents as well as the total and specific activities of marker enzymes in each fraction from the nephrectomized rat adrenals were practically unchanged from the controls. Further, the percentage distribution of renin, protein, and marker enzymes in fractions obtained from the nephrectomized groups showed an essentially similar pattern to that of the normals (Tables I and II). Taken collectively, these data suggest that renin is associated with a population different from the mitochondria and lysosomes.

To further separate renin-related particles from mitochondria, lysosomes or other cell debris, the $\mathrm{P}_{2}$ pellet prepared from normal and nephrectomized rat adrenals was separately subjected to gradient centrifugation in 35\% (vol/vol) Percoll. After centrifugation, two bands were observed in the centrifugation tubes. The first band, near the top of the gradient, appeared light brown. The second, at the bottom, appeared lighter and more diffuse, and was much more dense in nephrectomized groups as compared with that of the normals. Representative results of the analysis of fractions collected from the top of the tubes are illustrated in Fig. 1. In the case of normal rat adrenals (Fig. $1 \mathrm{~A}$ ), the first band, which had the lowest density, contained large quantities of acid phosphatase and succinate dehydrogenase (Table III). The band at the bottom of the gradient contained renin activity of $>60 \%$ of the total activity recovered from the entire gradient. This band was also partially associated with acid phosphatase, and with only minor contamination by succinate dehydrogenase.

In the case of nephrectomized adrenals (Fig. $1 \mathrm{~B}$ ), an al-

Table I. Subcellular Distribution of Immunoreactive Renin and Reference Enzymes from Adrenal Capsules of Control Rats

\begin{tabular}{|c|c|c|c|c|c|c|c|c|c|}
\hline & \multirow{2}{*}{$\begin{array}{c}\text { Original } \\
\text { homogenate }\end{array}$} & \multicolumn{7}{|c|}{ Fractions obtained by differential centrifugation } & \multirow[b]{2}{*}{ Recovery } \\
\hline & & $\mathbf{P}_{\mathbf{0}}$ & $\mathbf{P}_{1}$ & $\mathbf{P}_{\mathbf{2}}$ & $S_{2}$ & $\mathbf{P}_{2}^{\prime}$ & $\mathbf{M}$ & $\mathbf{s}$ & \\
\hline & & & & & & & & & $\%$ \\
\hline Renin & $20.12 \pm 0.52$ & $0.45 \pm 0.09$ & $0.14 \pm 0.01$ & $10.99 \pm 0.27$ & $1.76 \pm 0.35$ & $1.58 \pm 0.09$ & $1.01 \pm 0.14$ & $1.17 \pm 0.51$ & $85.0 \pm 1.2$ \\
\hline Acid phosphatase & $11.80 \pm 2.13$ & $0.82 \pm 0.22$ & $0.50 \pm 0.13$ & $2.81 \pm 0.88$ & $4.75 \pm 0.50$ & $0.74 \pm 0.06$ & $0.70 \pm 0.17$ & $0.98 \pm 0.37$ & $96.4 \pm 4.9$ \\
\hline \multicolumn{10}{|l|}{ Succinate } \\
\hline dehydrogenase & $6.40 \pm 0.08$ & $0.75 \pm 0.19$ & $1.11 \pm 0.13$ & $3.40 \pm 0.28$ & $0.27 \pm 0.14$ & $0.10 \pm 0.04$ & 0 & $0.10 \pm 0.05$ & $89.7 \pm 4.7$ \\
\hline Protein & $5.83 \pm 0.22$ & $0.65 \pm 0.14$ & $0.44 \pm 0.08$ & $1.03 \pm 0.02$ & $1.77 \pm 0.45$ & $0.34 \pm 0.05$ & $0.40 \pm 0.06$ & $1.59 \pm 0.58$ & $106.7 \pm 6.3$ \\
\hline
\end{tabular}

Enzyme activities and protein contents in original homogenate and in each fraction volume. Units are nanograms of angiotensin $\mathrm{I} / \mathrm{hour}$ for renin, absorbancy at $410 \mathrm{~nm} / \mathrm{h}$ for acid phosphatase, decrease of absorbancy at $450 \mathrm{~nm} / 16 \mathrm{~h}$ for succinate dehydrogenase and milligrams for protein. Values are means \pm SE of three different experiments. 
Table II. Subcellular Distribution of Immunoreactive Renin and Reference Enzymes from Adrenal Capsules of Nephrectomized Rats

\begin{tabular}{|c|c|c|c|c|c|c|c|c|c|}
\hline & \multirow{2}{*}{$\begin{array}{c}\text { Original } \\
\text { homogenate }\end{array}$} & \multicolumn{7}{|c|}{ Fractions obtained by differential centrifugation } & \multirow[b]{2}{*}{ Recovery } \\
\hline & & $\mathbf{P}_{\mathbf{0}}$ & $\mathbf{P}_{\mathbf{1}}$ & $\mathbf{P}_{\mathbf{2}}$ & $\mathbf{S}_{\mathbf{2}}$ & $\mathbf{P}_{2}^{\prime}$ & $\mathbf{M}$ & $\mathbf{s}$ & \\
\hline & & & & & & & & & $\%$ \\
\hline Renin & $241.23 \pm 7.59$ & $3.14 \pm 0.10$ & $5.59 \pm 0.89$ & $151.50 \pm 7.77$ & $23.40 \pm 4.08$ & $5.58 \pm 1.39$ & $7.01 \pm 0.20$ & $4.49 \pm 0.15$ & $83.2 \pm 5.5$ \\
\hline Acid phosphate & $8.44 \pm 1.78$ & $1.22 \pm 0.13$ & $0.50 \pm 0.05$ & $2.02 \pm 0.63$ & $3.29 \pm 0.06$ & $0.89 \pm 0.39$ & $0.76 \pm 0.23$ & $0.92 \pm 0.21$ & $113.6 \pm 4.5$ \\
\hline \multicolumn{10}{|l|}{ Succinate } \\
\hline dehydrogenase & $6.23 \pm 0.22$ & $0.83 \pm 0.30$ & $1.00 \pm 0.04$ & $3.63 \pm 0.25$ & $0.25 \pm 0.24$ & $0.09 \pm 0.07$ & 0 & $0.01 \pm 0.00$ & $92.0 \pm 6.0$ \\
\hline Protein & $7.01 \pm 0.56$ & $0.76 \pm 0.33$ & $0.56 \pm 0.26$ & $0.95 \pm 0.18$ & $2.25 \pm 0.76$ & $0.28 \pm 0.15$ & $0.37 \pm 0.20$ & $1.36 \pm 0.61$ & $93.2 \pm 4.74$ \\
\hline
\end{tabular}

Enzyme activities and protein contents in original homogenate and in each fraction volume. Units are nanograms of angiotensin $1 /$ hour for renin, absorbancy at $410 \mathrm{~nm} / \mathrm{h}$ for acid phosphate, decrease of absorbancy at $450 \mathrm{~nm} / 16 \mathrm{~h}$ for succinate dehydrogenase and milligram for protein. Values are means $\pm \mathrm{SE}$ of three different experiments.

A
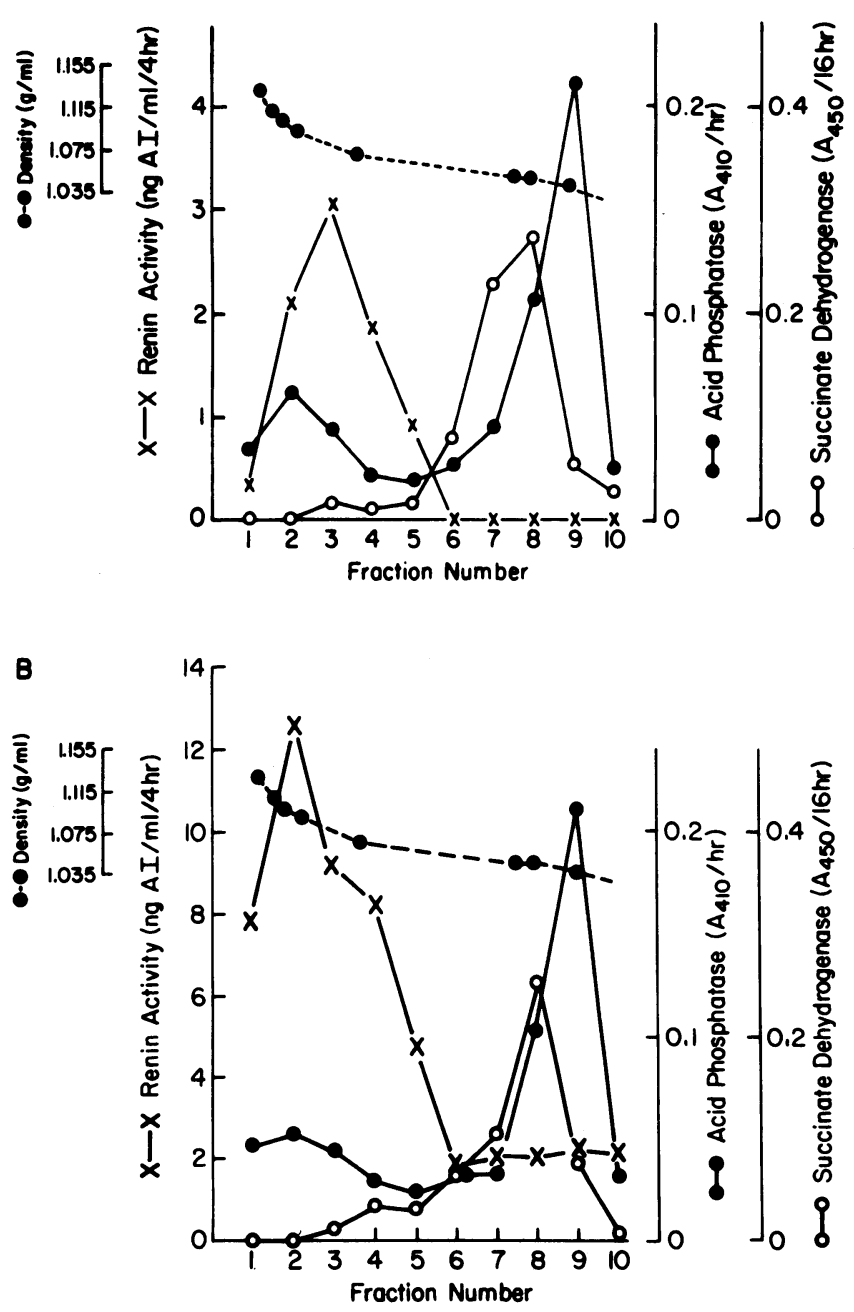

Figure 1. Typical distribution of renin and marker enzymes from the Percoll gradient of $P_{2}$ pellet obtained from differential centrifugation. Fractions $(0.8 \mathrm{ml})$ were collected from the top of the centrifugation tube. In each fraction, renin and marker enzymes' activities were measured as described in Methods. $(A)$ A representative result from normal rat adrenals; $(B)$ from bilaterally nephrectomized rat adrenals. most identical pattern of distribution of renin and marker enzymes was found on the gradient, and the pattern was highly reproducible (Table III). As compared with the data from normal rat adrenals, it is apparent that only renin activity was increased unequivocally in fractions corresponding to the heavier density, whereas no difference was observed in marker enzyme activity on the gradient between the two groups.

\section{Immunocytochemistry}

Localization of renin in the adrenal cortex. Adrenal cortex obtained from bilaterally nephrectomized rats showed strong immunostaining in the zona glomerulosa cells with antirenin antisera, as shown in Fig. 3. Staining was intense at antibody dilutions of 1:500 to 1:1,000 but disappeared at a dilution above $1: 4,000$. Whereas staining was also present, although less intense, in cells of the inner zona glomerulosa portion and in zona fasciculata, connective tissue elements and blood vessels in the capsule were unstained (Fig. 2).

Particles from Percoll density gradient. Examination of pellets from Percoll fractions of glutaraldehyde and osmiumfixed samples from both normal and nephrectomized animals demonstrated that the low density fractions consisted largely of mitochondria with small numbers of lysosomal or multivesicular bodies. Most mitochondria had only moderate electron density and appeared to be in the orthodox conformation (26). Pellets from high density fractions contained condensed mitochondria and a population of membrane-bounded, electrondense granules which increased in number in the nephrecto-

Table III. Modal Densities of Renin and Marker Enzymes on Percoll Density Gradient Centrifugation from Normal and Bilaterally Nephrectomized Groups

\begin{tabular}{lcc}
\hline \multicolumn{1}{c}{ Enzymes } & Normal group* & Nephrectomized group $^{*}$ \\
\hline Acid phosphatase & $1.050 \pm 0.003$ & $1.054 \pm 0.002$ \\
Succinate dehydrogenase & $1.056 \pm 0.002$ & $1.056 \pm 0.001$ \\
Renin & $1.086 \pm 0.004$ & $1.090 \pm 0.003$ \\
\hline
\end{tabular}

Values are the means $\pm S E$.

* Data from seven independent experiments.

${ }^{\ddagger}$ Data from six independent experiments. 


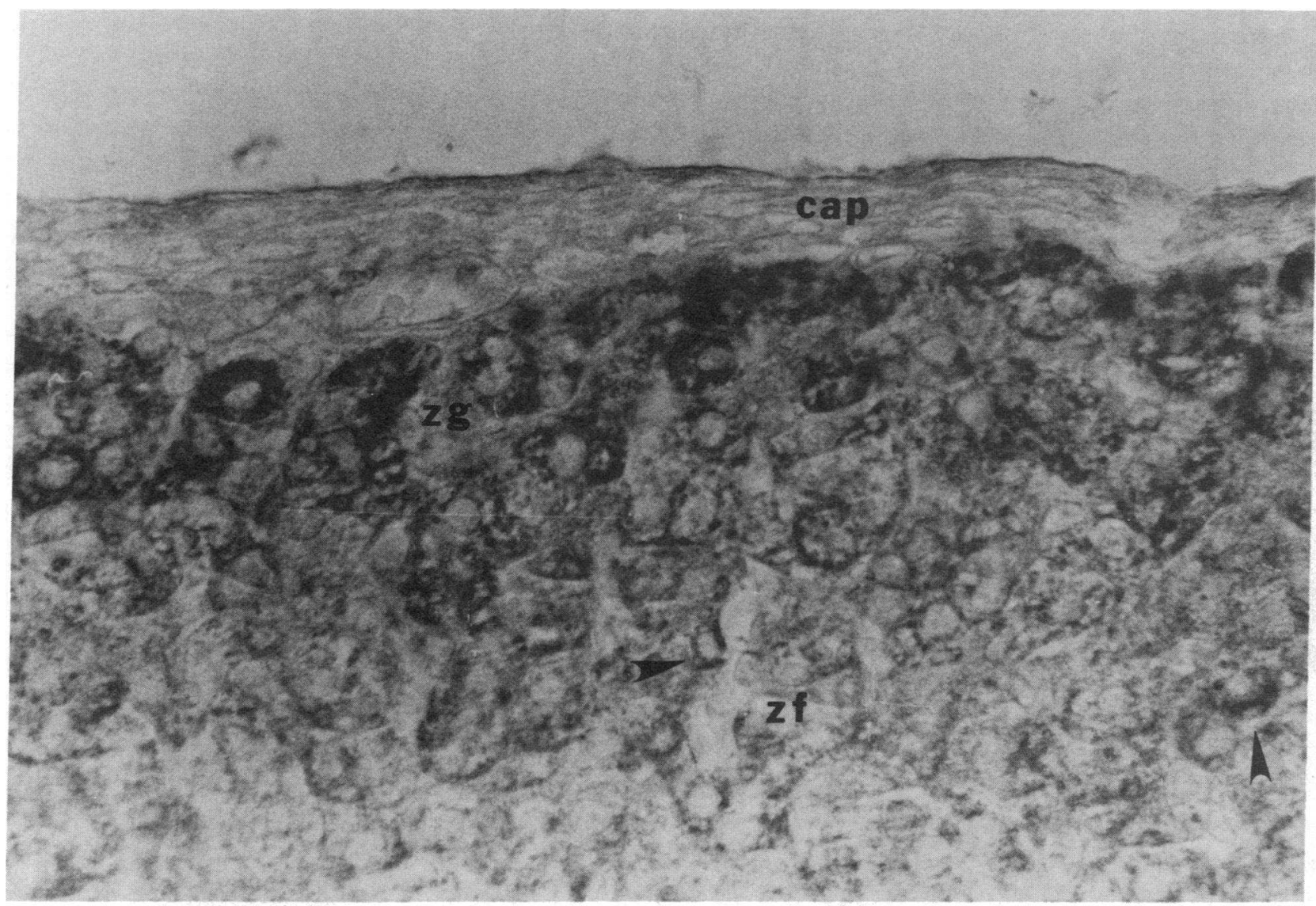

Figure 2. Immunohistochemical localization of renin in rat adrenal cortex. The first few layers of cells in the zona glomerulosa (zg) are intensely stained. Staining is also present, although less intense, in cells of the inner zona glomerulosa and in zona fasiculata ( $z f$; arrowheads). Connective tissue elements and blood vessels in the capsule (cap) are unstained. $\times 750$.

mized group (Fig. $3 \mathrm{~A}$ ). Granules ranged from $\sim 0.2$ to $0.7 \mu \mathrm{m}$ in diameter and presented either circular or elliptical profiles. Occasional granules contained a small membranous vesicle within (Fig. $3 A$ ).

Electron microscopic examination of sections from the mitochondria-rich low density fractions reacted with rabbit antirenin and goat antirabbit IgG-colloidal gold revealed a small number of randomly scattered gold particles (Fig. $3 \mathrm{~B}$ ). In the high density fraction with high renin activity, however, gold particles were localized to the electron-dense granules (Fig. $3 C$ ). When reacted with a 1:100 dilution for renin antiserum, most granules were overlain by 4-40 gold particles, although granules completely lacking gold particles were encountered on occasion. A similar distribution of colloidal gold was observed following treatment with the 1:1,000 dilution of primary antiserum, but the number of gold particles over granules was reduced. Control sections, treated with comparable dilutions of preimmune rabbit serum, showed no specific reaction. Scattered gold particles were present on control sections, similar to the distribution seen in low density fractions reacted with immune serum (Fig. $3 B$ ).

\section{Adrenal tissue culture}

The adrenal capsular tissues prepared from normal and nephrectomized rats were cultured in RPMI 1640 supplemented with bovine serum albumin $(0.1 \%$ in final concentration) for a period of $8 \mathrm{~h}$.
Fig. 4 shows representative results obtained from normal and nephrectomized rats. Renin release from adrenal capsular tissues progressed in a linear fashion over the incubation period of $8 \mathrm{~h}$ for both normal and nephrectomized groups. The cumulative amount of renin released into the culture media was significantly greater in nephrectomized rats than that in normal groups at each incubation period examined (Table IV). To further confirm if this release is a regulated process, we examined the effect of increased concentration of extracellular potassium $\left(10^{-2} \mathrm{M}\right)$, ACTH $\left(10^{-9}\right.$ to $\left.10^{-7} \mathrm{M}\right)$ and Ang II $\left(10^{-9}\right.$ to $10^{-7} \mathrm{M}$ ) on the renin release form capsular tissues of normal rat adrenals.

As shown in Table IV, renin release was slightly, but significantly, enhanced by increased concentration of extracellular potassium. It was also shown that Ang II stimulated markedly the renin release in a dose-dependent fashion; it increased the rate of secretion by $\sim+120 \%,+150 \%$, and $+220 \%$ over the control at the concentrations of $10^{-9}, 10^{-8}$, and $10^{-7} \mathrm{M}$, respectively. On the contrary, no significant change in renin release was observed by addition of various concentrations of ACTH (Table IV).

\section{Discussion}

The adrenal gland has been shown to possess renin-like activity (1-3). Initially, it was not clear whether the activity was due to the specific action of renin or a nonspecific action of acid 


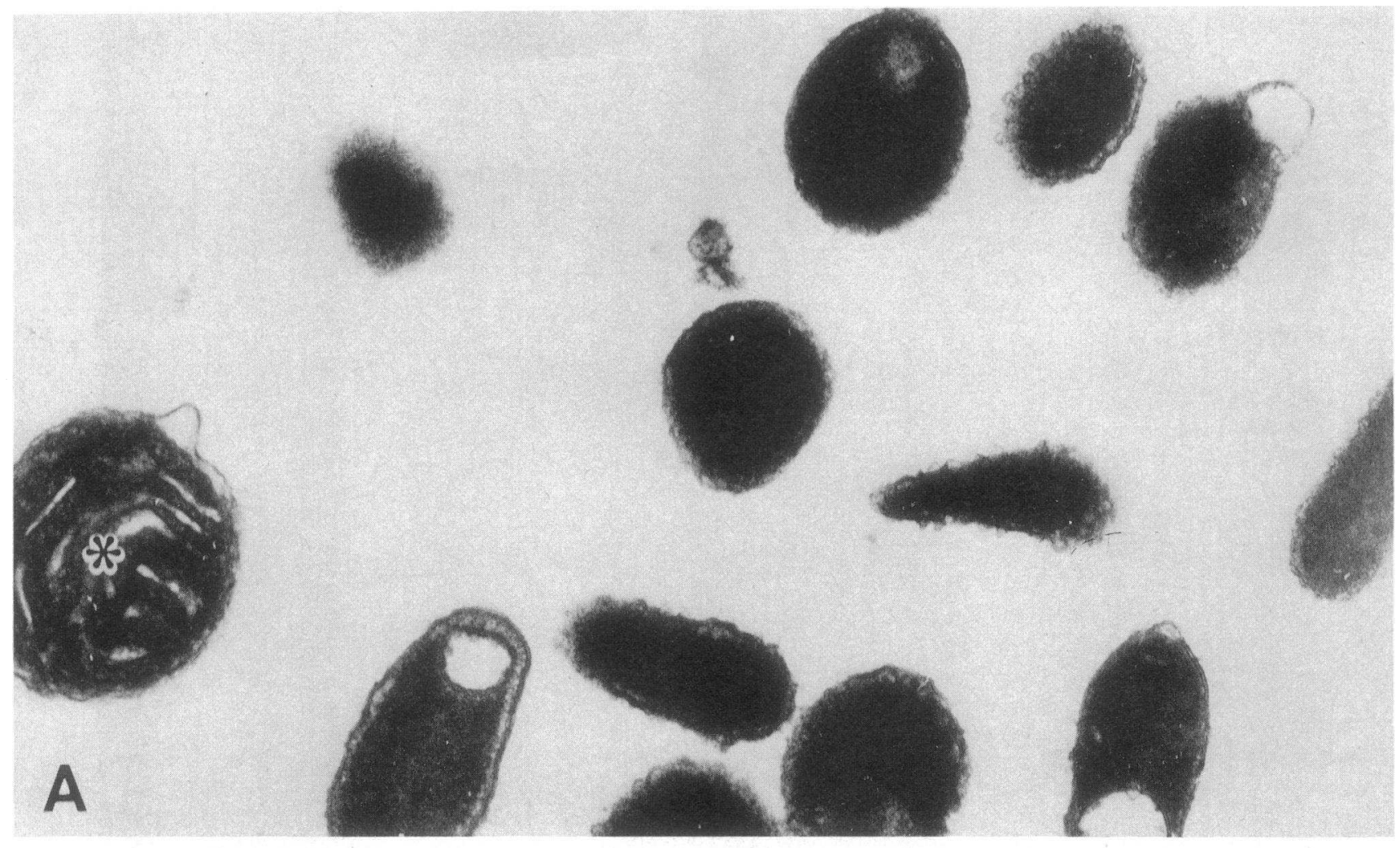

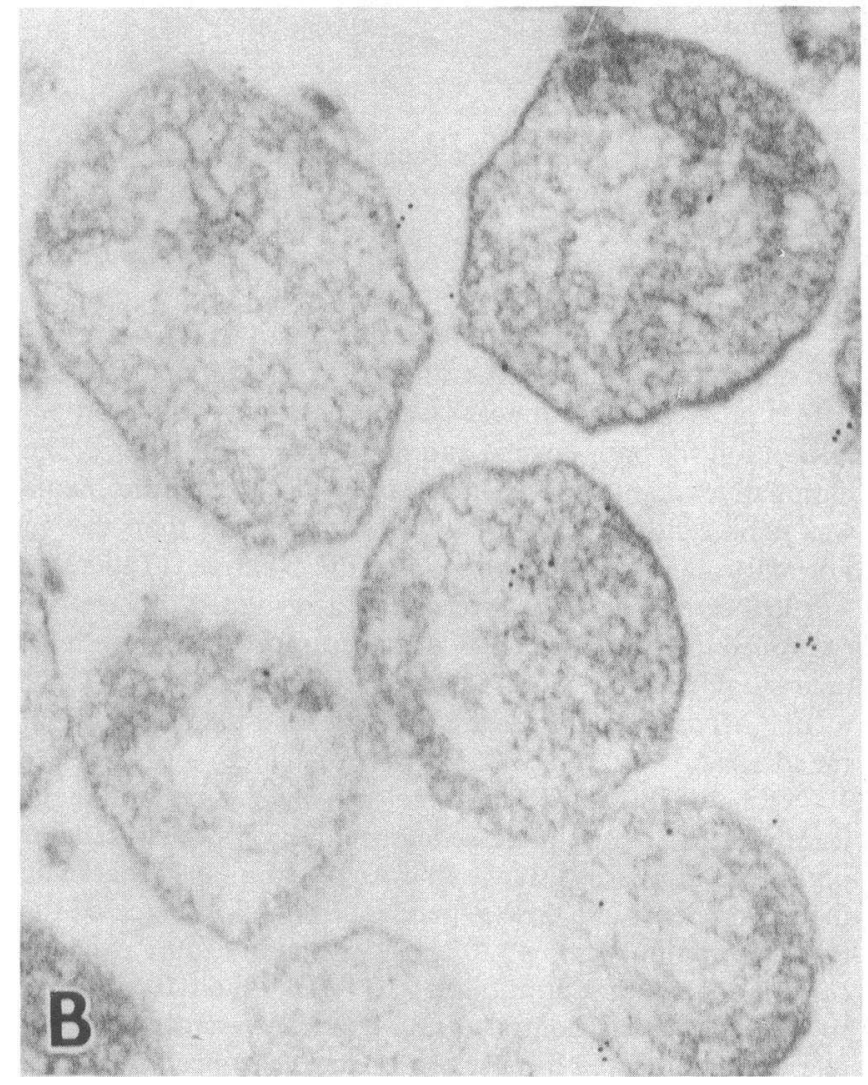

Figure 3. Electron micrographs of sections from Percoll density gradient fractions. $(A)$ Electron-dense granules and a condensed mitochondrion (*) from high density fraction of nephrectomized rat adrenal fixed in glutaraldehyde-osmium. $\times 72,000$. (B) Mitochondria in orthodox conformation from low density fraction reacted with a 1:100 dilution of rabbit anti-renin and goat anti-rabbit IgG-colloidal

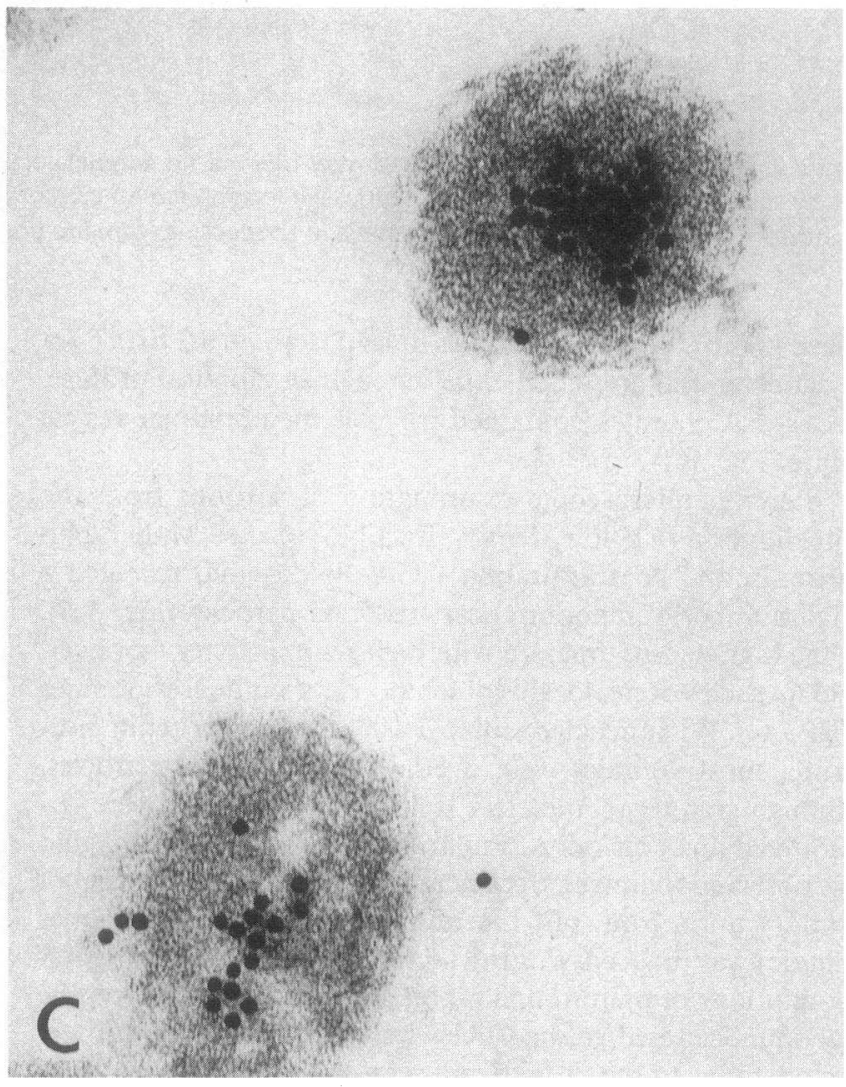

gold. A scattering of gold particles is seen over the section, but there is no specific localization. $\times 49,000$. (C) Granules in high density fraction reacted as in $B$. Numerous gold particles overlie the granules. $\times 135,000$. The diameter of the granules was between 0.2 and $0.7 \mu \mathrm{m}$, which is somewhat smaller than that of the renin secretory granules of rat kidney cortex (28). 


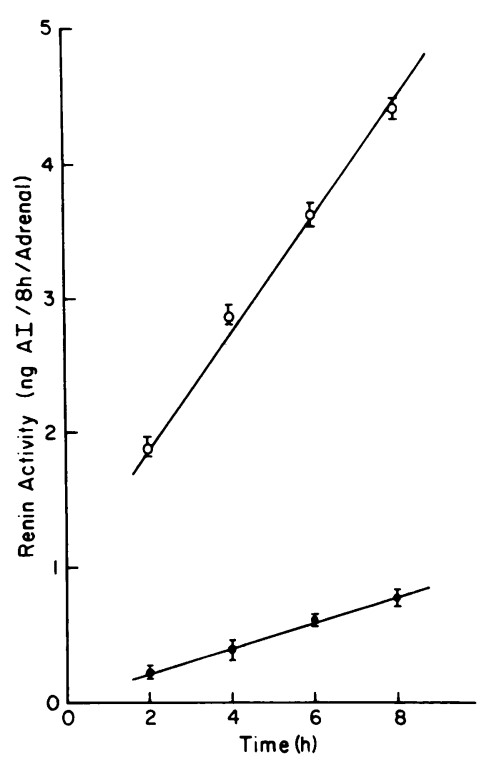

protease(s) such as cathepsin D. It is now widely accepted that a considerable part of the renin-like activity is due to the specific action of renin. The finding that nephrectomy elicits a

Table IV. Effect of Potassium Chloride, ACTH, and Angiotensin II on Renin Release from Cultured Rat Adrenal Capsular Tissues

\begin{tabular}{lcccc}
\hline \multicolumn{1}{c}{ Conditions } & $\begin{array}{c}\text { Number of } \\
\text { experiments }\end{array}$ & Renin activity & \% control & $P$ value $^{*}$ \\
\hline Control & 6 & $0.96 \pm 0.06$ & 100 & \\
Nephrectomy & 6 & $4.41 \pm 0.18$ & 461 & $<0.001$ \\
Control & 6 & $1.15 \pm 0.07$ & 100 & \\
$\begin{array}{l}\text { Potassium } \\
\text { chloride } 10^{-2} \mathrm{M}\end{array}$ & 6 & $1.67 \pm 0.19$ & 145 & \\
Control & 6 & $1.56 \pm 0.18$ & 100 & \\
ACTH & & & & \\
$\quad 10^{-9} \mathrm{M}$ & 6 & $1.63 \pm 0.16$ & 104 & $\mathrm{NS}$ \\
$10^{-8} \mathrm{M}$ & 6 & $1.94 \pm 0.39$ & 124 & $\mathrm{NS}$ \\
$\quad 10^{-7} \mathrm{M}$ & 6 & $2.02 \pm 0.35$ & 129 & $\mathrm{NS}$ \\
Control & 6 & $0.70 \pm 0.12$ & 100 & \\
Angiotensin II & & & & \\
$\quad 10^{-9} \mathrm{M}$ & 6 & $1.75 \pm 0.17$ & 249 & $<0.001$ \\
$10^{-8} \mathrm{M}$ & 6 & $1.97 \pm 0.23$ & 281 & $<0.001$ \\
$10^{-7} \mathrm{M}$ & 6 & $2.23 \pm 0.23$ & 319 & $<0.001$ \\
\hline
\end{tabular}

Values are given as means $\pm \mathrm{SE}$.

* Each culture dish contained capsular tissue from three adrenals in $1 \mathrm{ml}$ of medium.

‡ Cumulative values released into culture medium during entire incubation period of $8 \mathrm{~h}$, and expressed as ng angiotensin $\mathrm{I} / 8 \mathrm{~h}$ incubation with renin substrate $/ 8 \mathrm{~h}$ incubation of tissues/adrenal.

${ }^{\delta}$ Compared with control values. The standardized medium contained $0.5 \times 10^{-2} \mathrm{M}$ of $\mathrm{KCl}$. The capsular tissues were prepared from rat adrenals nephrectomized $32 \mathrm{~h}$ before experiments. NS denotes $P$ $>0.05$. marked increase in the renin activity of the adrenal cortex (6, 7), which was confirmed in the present study (Table II), indicates that the enzyme is endogenous to the adrenal rather than due to contamination by plasma renin of renal origin. In support of this, renin mRNA has been detected in the adrenal gland (10), giving firm evidence for intraadrenal production of renin.

As to regional distribution of renin in the adrenal, biochemical analysis has demonstrated that renin is contained mainly in the capsular (i.e., zona glomerulosa) tissue rather than the fasciculata-medullary portion $(6,7)$. The present finding that renin was immunostained most intensely in the zona glomerulosa cells (Fig. 3) further supports such biochemical observation, permitting us to use the capsular tissues as a source of renin in the adrenal.

Although recent studies have demonstrated that the adrenal renin is involved in the regulation of aldosterone production in vitro $(6,7,9)$, the precise significance of renin in the tissue is still in dispute. In the current study, as a step toward gaining better insight into the role of renin in the adrenal, we have examined the subcellular distribution of renin in the capsular tissue.

The differential centrifugation results show that most of the renin activity is located in the mitochondrial fraction, the identity of which was determined by the finding that most of the succinate dehydrogenase activity, a mitochondrial marker, was also found in this fraction. This not only is consistent with the notion that the renin is not due to plasma contamination, but also implies that the cytosol is not the principal site of storage of renin in the adrenal. This hypothesis was further tested by examining the distribution of renin and marker enzymes in the tissue from bilaterally nephrectomized animals, since nephrectomy is known as the most potent stimulator of adrenal renin. Our results confirm the interpretation that the renin is closely associated with components of the mitochondrial fraction but not with other subcellular organelles, inasmuch as the majority of renin activity was also found in this fraction and the distribution pattern of the enzyme including marker enzymes was essentially similar to that in the control animals (Fig. 1).

On the basis of our previous findings, however, that renins in the human adrenal cortex (4) and in the hog anterior pituitary (27) were likely to be related to granule-like compartments, we postulated that the adrenal renin is localized in particles with granular structure. Indeed, in the present study it was shown that bilateral nephrectomy elicited a marked increase of renin activity, but did not alter either the total or specific activities of the mitochondrial and lysosomal markers (Tables I and II), suggesting that the nephrectomy-induced increment in the renin activity is associated with some compartment other than these organelles.

Recently, we have developed a new method for purification of renin granules from homogenate of rat kidney cortex by Percoll density gradient (28). Application of a Percoll density gradient centrifugation has shown successful separation of granules from other subcellular organelles in many tissue such as adrenal medulla (29) and atria (30). In the current study, we thus employed this method for further resolution of the subcellular compartments in the mitochondrial fraction. Our results clearly show that renin in rat adrenal is evidently not associated with mitochondrial and lysosomal markers, indicating that the renin is not a product related to mitochondria 
and lysosomes. However, the acid phosphatase activity partially coexisted with the renin activity, which indicates slight contamination by high-density lysosomes $(27,30)$. Although earlier reports $(31,32)$ concerning renin granules in rat kidney suggested the coexistence of renin and lysosomal enzymes in "renin granules," the present result seems to exclude the possibility that the renin appeared in the heavier density region is lysosomes or a lysosome-related enzyme, as it was found that only renin activity specifically elevated after nephrectomy whereas the activity of lysosomal enzyme remained unchanged as compared with the normals (Fig. 2, $A$ and $B$ ). Furthermore, the density of the adrenal renin band in Percoll, for both normal and nephrectomized groups, is close to, although slightly lower than, that of kidney renin secretory granules $(1.11$ to $1.15 \mathrm{~g} / \mathrm{ml})$ as we previously reported $(28)$.

However, it is also possible that the renin is contained within nonlysosomal endocytotic vesicles as the result of specific renin uptake. Therefore, in the current study, an additional effort was made to examine the structure of renin-containing compartments in the Percoll band by electron microscopic study coupled with immunochemical staining technique. Our results have clearly demonstrated that there exist dense granules in this band. More important, the population of these granules was increased in the nephrectomized group as compared with the normals along with a simultaneous increase in the renin activity. The diameter of these granules was between 0.2 and $0.7 \mu \mathrm{m}$, which is somewhat smaller than, but in the range $(0.4-1.4 \mu \mathrm{m})$ of, that of the renin secretory granules of rat kidney cortex (28). Moreover, it was shown by using immunogold labeling that most of these granules reacted with specific antibody raised against pure rat kidney renin. Thus, these results provide evidence for the presence of renin-containing specific granules in the adrenal.

In the current study, because of the limited activity of renin, we were not able to analyze the biochemical properties of renin in these granules. However, the presence of renincontaining vesicles suggests that the adrenal secretes renin into the extracellular space. To test this hypothesis, we further examined whether renin release can occur from the adrenal.

Our results demonstrate that renin is released from the adrenal tissues in a time-dependent fashion. Further, the amount of released renin was apparently greater in the culture from nephrectomized groups than that from normals. Assuming that renin in the adrenal is secreted from the granules by exocytotic mechanism, the larger amount of renin released from the nephrectomized rat adrenals is in line with the observation of the increased population of renin-containing granules in these animals.

It has been recognized that cellular export of proteins can occur via two secretory pathways, referred to as "regulated" and "constitutive" (33), and proteins secreted by the regulated pathway are stored in secretory granules and thereby become available for release in response to appropriate secretagogues. In view of this concept, we examined the effect of potassium chloride, Ang II, and ACTH, all of which are known to affect the content of adrenal renin $(9,25)$, on renin release from the adrenal. Although our data are only preliminary, it was shown that potassium chloride and, unexpectedly, Ang II stimulated the renin release whereas ACTH did not (Table IV). The clarification of the exact mechanism by which the release of renin is stimulated by potassium chloride and Ang II requires further studies. However, it is generally accepted that calcium stimu- lates exocytotic release of enzymes, neurotransmitters and hormones (34) and that Ang II as well as potassium stimulate calcium uptake and influx into intracellular space $(35,36)$. We observed recently that protein synthesis inhibitor cycloheximide did not influence this Ang II-induced renin release (unpublished observations). In addition, we found that the release was increased by calcium ionophores (A23187 or ionomycin) and synergistically by the addition of phorbol ester (unpublished observations). Ang II $\left(10^{-9}\right.$ to $\left.10^{-7} \mathrm{M}\right)$ has been shown to increase intracellular calcium in the rat adrenal glomerulosa cells in a dose-dependent manner (37). It was also shown that either ACTH or cyclic AMP (cAMP) did not increase intracellular calcium in these cells (37). Furthermore, we observed recently that adenylate cyclase stimulator, forskolin, failed to stimulate renin release from the cultured adrenal cortex (unpublished observations). Thus, it would be reasonable to speculate that Ang II stimulates the adrenal renin release probably by elevating intracellular calcium rather than by stimulating new synthesis of renin, though the latter possibility could not entirely be eliminated. A cAMP-mediated mechanism does not seem operative in the release, inasmuch as ACTH failed to promote the renin release and Ang II inhibits adenylate cyclase in most of the Ang II-responsive tissues including adrenal zona glomerulosa cells $(38,39)$, vasculature $(40)$, kidney $(41)$, and pituitary (42). As to the effect of potassium chloride, it is well accepted that, in rat adrenal glomerulosa cells in contrast to other types of cells, $10 \mathrm{mM}$ potassium chloride which was used in the present study attains the maximal potassium-dependent response and consequent maximal intracellular cytosolic calcium increase $(38,43)$. Thus, it is likely that calcium-mediated mechanism is most responsible for the effect of potassium chloride on the adrenal renin release. The lack of stimulation by Ang II and potassium rather than inhibition is in direct contrast to the renin secretory mechanisms in the kidney (44-47).

These findings strongly support the idea that renin release from the adrenal is under the control of a regulated process, and thus, provide firmer evidence for the presence of reninsecretory granules in the adrenal.

Finally, accumulating evidence suggests that in extrarenal tissues or cells, renin and Ang II coexist in the same cells (22, $48,49)$. Further, it has been demonstrated in in vitro experiments using the culture system $(50,51)$ that it is predominantly Ang II rather than renin that is secreted from some of the cells. These findings indicate that renin performs its intracellular function to produce Ang II. Based on the present results, however, it seems likely that the adrenal renin is secreted in response to an appropriate stimulus rather than performing its possible intracellular function to produce Ang II. Since we are not certain whether angiotensin is secreted with renin from the adrenal gland, further studies are required to resolve this intriguing issue.

In summary, the data reported here have demonstrated the presence of renin-secretory granules in the rat adrenal gland. The population of such secretory granules was increased by bilateral nephrectomy, concomitant with elevation of adrenal renin activity evoked by the manipulation. Further, it has been shown that the adrenal secretes renin into the extracellular space by a controlled process, and therefore, it is possible that the secreted renin generates Ang II in the circulation. This implies that the adrenal could be a source of renin-like activity in plasma observed in anephric humans and animals (12, 52, 
53). Moreover, since the renin secreted in the outer cortical layer will flow into the adrenal medulla, it is possible that adrenal renin secretion may modulate secretion of various hormones from the medullary cells.

Further studies will be necessary to determine the precise mechanism of synthesis of renin-secretory granules in the adrenal gland and a factor or factors that regulate its secretion. These studies could be important for our better understanding of the role of extrarenal renin including the adrenal enzyme in circulating Ang II production and, hence, in blood pressure regulation under diverse physio-pathological states.

\section{Acknowledgments}

The authors are grateful to Mr. Edward Price, Jr. and Mrs. Virginia Winfrey for their technical assistance and Mrs. Jeanne Williams for editorial assistance.

This study was supported by U.S. Public Health Service grants HL-14192, HL 35323, and Center Grant HD 05797 from the National Institutes of Health.

\section{References}

1. Hayduck, K., R. R. Boucher, and J. Genest. 1970. Renin activity content in various tissues of dogs under different physio-pathological state. Proc. Soc. Exp. Biol. Med. 134:252-257.

2. Ganteen, D., U. Ganten, S. Kubo, P. Granzer, W. Nowaczynski, R. R. Boucher, and J. Genest. 1974. Iso-renin in rat adrenal glands: influence of sodium, potassium and pituitary hormones. Am. J. Physiol. 227:224-229.

3. Naruse, M., K. Naruse, T. Inagaki, and T. Inagami. 1984. Immunoreactive renin in mouse adrenal gland: localization in the inner cortical region. Hypertension. 6:275-280.

4. Naruse, M., C. R. Sussman, K. Naruse, R. V. Jackson, and T. Inagami. 1983. Renin exists in human adrenal tissue. J. Clin. Endocrinol. Metab. 57:482-487.

5. Mizuno, K., M. Ojima, S. Hashimoto, M. Tani, S. Niimura, N. Kunii, R. Yabe, H. Watari, T. Inagami, and S. Fukuchi. 1987. Multiple forms of immunoreactive renin in human adrenocortical tumour tissue from patients with primary aldosteronism. Clin. Sci. 72:699704.

6. Doi, Y., K. Atarashi, R. Franco-Saenz, and P. J. Mulrow. 1983. Adrenal renin: a possible regulator of aldosterone production. Clin. Exp. Hypertension. A5:1119-1125.

7. Doi, Y., K. Atarashi, R. Franco-Saenz, and P. J. Mulrow. 1985. Effect of changes in sodium or potassium balances, and nephrectomy, on adrenal renin and aldosterone concentrations. Hypertension. 6(Suppl. I):I-24-I-29.

8. Inagami, T., K. Pandey, M. Nakamaru, J. C. McKenzie, K. S. Misono, K. Naruse, and M. Naruse. 1984. Advances in the biochemistry of the renin angiotensin system: intracellular renin angiotensin system in rat adrenal zona glomerulosa cells and rat testicular Leydig cells. In Endocrinology. F. Labrie and L. Proulx, editors. Elsevier Science Publishers, Amsterdam, 399-402.

9. Nakamaru, M., K. S. Misono, M. Naruse, R. J. Workman, and T. Inagami. 1985. A role of the adrenal renin-angiotensin system in the regulation of potassium-stimulated aldosterone production. Endocrinology. 117:1772-1778.

10. Ohkubo, H., K. Nakayama, T. Tanaka, and S. Nakanishi. 1986. Tissue distribution of rat angiotensinogen mRNA and structural analysis of its heterogeneity. J. Biol. Chem. 261:319-323.

11. Catt, K. J., M. D. Cain, and J. P. Coghlan. 1967. Measurement of angiotensin II in blood. Lancet. ii:1005-1007.

12. Yu, R., J. Andrews, S. L. Skinner, and J. B. Best. 1972. Renin in anephric man. Am. J. Med. 52:707-711.
13. Semple, P. F., A. S. Boyd, P. M. Dawes, and J. J. Morton. 1976. Angiotensin II and its heptapeptide (2-8), hexapeptide (3-8), and pentapeptide (4-8) metabolites in arterial and venous blood of man. Circ. Res. 39:671-678.

14. ManIn'TVeld, A. J., G. J. Wenting, and M. A. D. H. Schalekamp. 1979. Does captopril lower blood pressure in anephric patients? Br. Med. J. 2:1110.

15. Mizuno, K., M. Ojima, M. Gotoh, S. Hashimoto, and S. Fukuchi. 1985. True renin in human pituitary tissue. J. Neurochem. 44:633-636.

16. Mizuno, K., M. Ojima, S. Hashimoto, and S. Fukuchi. 1985. Renin and angiotensin-converting enzyme in human neuroblastoma tissue. J. Neurochem. 45:626-629.

17. Takii, Y., A. F. S. Figueiredo, and T. Inagami, 1985. Application of immunochemical methods to the identification and characterization of rat kidney inactive renin. Hypertension. 7:236-243.

18. Haber, E., T. Koerner, L. B. Page, B. Kliman, and A. Purnode. 1969. Application of a radioimmunoassay for angiotensin $I$ to the physiologic measurements of plasma renin activity in normal human subjects. J. Clin. Endocrinol. Metab. 29:1349-1355.

19. Ostrowski, W., and A. Tsugita. 1961. Purification of acid phosphomonoesterase from the human prostrate gland. Arch. Biochem. Biophys. 94:68-81.

20. Slater, E. C., and W. D. Bonner. 1952. The effect of fluoride on the succinic oxidase system. Biochem. J. 52:185-195.

21. Lowry, O. H., N. J. Rosebrough, A. L. Farr, and R. J. Randall. 1951. Protein measurement with the Folin phenol reagent. J. Biol. Chem. 193:265-275.

22. McKenzie, J. C., K. Naruse, and T. Inagami. 1985. The reninangiotensin system in the rat anterior pituitary: colocalization of renin and angiotensin II in gonadotrophs. Anat. Rec. 212:161-166.

23. Bendayan, M., and M. Zollinger. 1983. Ultrastructural localization of antigenic sites on osmium-fixed tissues applying the protein A-gold technique. J. Histochem. Cytochem. 31:101-109.

24. Watson, A. Y., J. K. Anderson, K. Siminoski, J. E. Mole, and R. A. Murphy. 1985. Cellular and subcellular colocalization of nerve growth factor and epidermal growth factor in mouse submandibular glands. Anat. Rec. 213:365-376.

25. Baba, K., Y. Doi, R. Franco-Saenz, and P. J. Mulrow. 1986. Mechanism by which nephrectomy stimulates adrenal renin. Hypertension. 8:997-1002.

26. Hackenbrock, C. R. 1968. Ultrastructural bases for metabollically linked mechanical activity in mitochondria. II. Electron transport-linked ultrastructural transformations in mitochondria. J. Cell Biol. 37:345-369.

27. Grammer, R. T., M. Naruse, and T. Inagami. 1983. The subcellular distribution of renin in hog anterior pituitary. Endocrinology. 113:344-347.

28. Kawamura, M., J. C. McKenzie, L. H. Hoffman, I. Tanaka, M. Parmentier, and T. Inagami. 1986. The storage form of renin in renin granules from rat kidney cortex. Hypertension. 8:706-711.

29. Meyer, D., and M. Burger. 1979. Isolation of a protein from the plasma membrane of adrenal medulla which binds to secretory vesicles. J. Biol. Chem. 254:9854-9859.

30. Thibault, G., R. Garcia, J. Gutkowska, J. Bilodeau, C. Lazure, N. G. Seidah, M. Chrétien, J. Genest, and M. Cantin. 1987. The propeptide $\mathrm{Asn}^{1}-\mathrm{Tyr}^{126}$ is the storage form of rat atrial natriuretic factor. Biochem. J. 241:265-272.

31. Gomba, S. Z., and B. M. Soltesz. 1969. Histochemistry of lysosomal enzymes in juxtaglomerular cells. Experientia (Basel). 25:513.

32. Fisher, E. R. 1966. Lysosomal nature of juxtaglomerular granules. Science (Wash. DC). 152:1752-1753.

33. Tartakoff, A., and P. Vassalli. 1978. Comparative studies of intracellular transport of secretory proteins. J. Cell Biol. 79:694-707.

34. Rubin, R. P. 1970. The role of calcium in the release of neurotransmitter substances and hormones. Pharmacol. Rev. 22:389-428.

35. Fakunding, J. C., and K. J. Catt. 1977. Dependence of aldoste- 
rone stimulation in adrenal glomerulosa cells on calcium uptake: effects of lanthanum and verapamil. Endocrinology. 107:1345-1353.

36. Elliott, M. E., and T. L. Goodfriend. 1981. Angiotensin alters ${ }^{45} \mathrm{Ca}^{2+}$ fluxes in bovine adrenal glomerulosa cells. Proc. Natl. Acad. Sci. USA. 78:3044-3048.

37. Braley, L. M., A. I. Menachery, E. M. Brown, and G. H. Williams. 1986. Comparative effect of angiotensin II, potassium, adrenocorticotropin, and cyclic adenosine 3',5'-monophosphate on cytosolic calcium in rat adrenal cells. Endocrinology. 119:1010-1019.

38. Marie, J., and S. Jard. 1983. Angiotensin II inhibits adenylate cyclase from adrenal cortex glomerulosa zone. FEBS (Fed. Eur. Biochem. Soc.) Lett. 159:97-101.

39. Woodcock, E. A., and C. I. Johnston. 1984. Inhibition of adenylate cyclase by angiotensin II in rat adrenal glomerulosa cells. Endocrinology. 115:337-341.

40. Anand-Srivastava, M. B. 1983. Angiotensin II receptors negatively coupled to adenylate cyclase in rat aorta. Biochem. Biophys. Res. Commun. 117:420-428.

41. Woodcock, E. A., and C. I. Johnston. 1982. Inhibition of adenylate cyclase by angiotensin II in rat renal cortex. Endocrinology. 111:1687-1691.

42. Marie, J., R. C. Gaillard, P. Schoenenberg, S. Jard, and J. Bockaert. 1985. Pharmacological characterization of the angiotensin receptor negatively coupled with adenylate cyclase in rat anterior pituitary. Endocrinology. 116:1049-1050.

43. Connor, J. A., M. C. Cornwalls, and G. H. Williams. 1987. Spatically resolved cytosolic calcium response to angiotensin II and potassium in rat glomerulosa cells measured by digital imaging techniques. J. Biol. Chem. 262:2919-2927.

44. Michelakis, A. M., J. Caudle, and G. W. Liddle. 1969. In vitro stimulation of renin production by epinephrine, norepinephrine, and cyclic AMP. Proc. Soc. Exp. Biol. Med. 130:748-753.

45. Reid, I. A., J. R. Stockigt, A. Goldfien, and W. F. Ganong. 1972. Simulation of renin secretion in dog by theophyllin. Eur. J. Pharmacol. 17:325-332.

46. Campbell, W. B., R. M. Graham, and E. K. Jackson. 1979. Role of renal prostaglandins in sympathetically mediated renin release in the rat. J. Clin. Invest. 64:448-456.

47. Vander, A. J., and G. W. Geelhoed. 1965. Inhibition of renin secretion by angiotensin II. Proc. Soc. Exp. Biol. Med. 120:339-343.

48. Naruse, K., T. Inagami, M. R. Celio, R. J. Workman, and Y. Takii. 1982. Immunohistochemical evidence that angiotensins I and II are formed by intracellular mechanism in juxtaglomerular cells. $\mathrm{Hy}$ pertension. 4(Suppl. II):II-70-II-74.

49. Okamura, T., D. L. Clemens, and T. Inagami. 1981. Renin, angiotensins and angiotensin-converting enzyme in neuroblastoma cells: evidence for intracellular formation of angiotensins. Proc. Natl. Acad. Sci. USA. 78:6940-6943.

50. Okamura, T., D. L. Clemens, and T. Inagami. 1984. Generation of angiotensins in cultured pheochromocytoma cells. Neurosci. Lett. 46:151-156.

51. Pandey, K. N., and T. Inagami. 1986. Regulation of renin angiotensins by gonadotrophic hormones in cultured Leydig tumor cells: release of angiotensin but not renin. J. Biol. Chem. 261:39343938.

52. Weinberger, M. H., M. B. Wade, W. Aoi, T. Usa, M. Dentino, F. Luft, and C. E. Grim. 1977. An extrarenal source of 'renin-like' activity in anephric man. Circ. Res. 40(Suppl. I):I1-I4.

53. Sealey, J. E., R. P. White, J. H. Laragh, and A. L. Rubin. 1977. Plasma prorenin and renin in anephric patients. Circ. Res. 41(Suppl. II):II17-II21. 